\title{
THE DECIBEL LEVELS OF TV AND THE ELUSIVE SOCIAL WILL
}

\author{
Dr. K. R. Subramanian* \\ *Professor of Management and Senior Consultant - Thinketh Labs
}

\section{*Corresponding Author: -}

\begin{abstract}
: -
There is no dearth of media TV channels for the news of happenings around us. Through the din and noise of the TV commercials and the intermittent serials, we get news trickling down, often not any events or historic moments but the political cog mire of parliamentary or legislative arguments and the media interviews trying to brow beat any politician. Or the so called discussion in which the decibel levels of shouting matches take place! ; The media has a pet phrase 'the public wants to know', but often it may the least of interest for common people to know. The people at large would like to know if there is a fall in vegetable or grocery prices or improvement in industrial production or employment. But people often have to content with the Political or Advertisement Commercial noise! What people want to know is when this will stop and there will be realistic report of news. It is a nightmare experience for the TV and media viewers to contend with rising noise level often leading to switching off. Social will is absolutely necessary. This article is to find out if there is any solution for this problem!
\end{abstract}

Key words: - Noise of TV commercials and programs, high decibel levels leading to confusion to comprehend, nightmarish experience, is there an end of the tunnel view? 


\section{INTRODUCTION}

All of us are familiar with the role of media particularly the TV. There is hardly any house hold without a TV. About 75\% of the urban households and 33\% of rural households own a TV. The TV viewership will be higher since in the rural areas neighbors would see the TV in the nearby house hold. The TV viewing habits differ from house holder to house holder and even among the people of the house like the wage earners and the housewives and the younger children of the house either going to school or college. Traditionally the TV used to be viewed by all the family members together in the evening for entertainment after hard day's work and wear. Today the viewership has dramatically changed due to occupational considerations, dispersal of human settlements and the concentration of population of working people in metropolitan areas. The viewership time is also slowly shifting to evenings to late evening hours extending to night. While these developments, along with the changing interest of younger generations of people with their digital aids is considerably changing TV programs in terms of content and delivery.

As consumers increasingly watch videos across all devices and screens, it's clear that the wall between linear TV and over-the-top (OTT) video is getting dismantled. Consumers of nearly all age groups are watching less traditional television, which is starting to negatively affect even the most secure of TV strongholds. But none of this means that TV is dying. It does, however, mean that the definition is changing. Millennials are most likely to refer to any content they can watch on any device - television, laptop, smart phone, or tablet - as "TV." This development does raise the question what is the future of normal TV? Generation Z-focused companies such as Awesomeness. TVs have designed their business models on the TV shift, according to Rebecca Glashow, the company's head of worldwide distribution, Awesomeness TV. While legacy networks might be handcuffed by contractual obligations that limit cross-platform content rights, her company has established a business model appropriate for their target audience that is multiplatform at its core. Quality, unique content are table stakes. No matter how easy you make the distribution of content, if that content fails to engage the audience, your efforts will be for naught. "TV needs to innovate, decline or die."

Creating compelling content is not only expensive, often involving trial and error, it is time-consuming. But the risk of not focusing on the development of unique content is greater than spending time, money and creative capital on it and risking failure. Small is nimble, and yet bigger may be better. There are three challenges that place stress on smaller networks: increased competition, the cost of doing business and the fight for distribution. While the fight for distribution may be reduced with the vastness of the IP that enables nimble smaller networks to expand their distribution, the first two challenges may see the demise of many smaller niche networks, according to some.

We live in a noisy world. Young and old alike are beset by sounds over which we may have little or no control: power mowers, leaf blowers, snow blowers, car and house alarms, sirens, motorcycles, Jet Skis, loudspeakers, even movie previews. Many "modern" restaurants have opted for noise enhancement instead of abatement. And try having a conversation in a school cafeteria at lunchtime. Any time you need to shout to be heard by someone near you, your hearing is most likely to be in a decibel danger zone. 


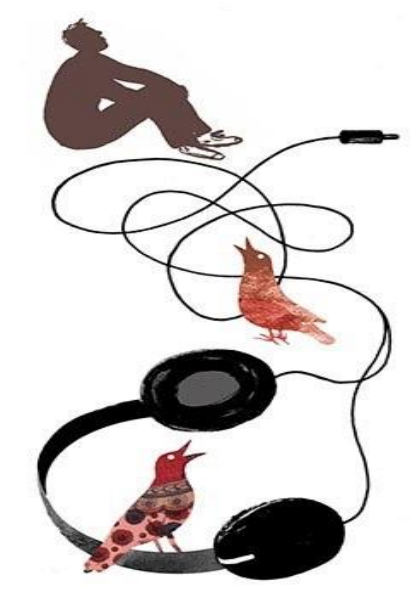

Figure 1: We live in a noisy world

As if environmental noise were not enough, now we besiege children with noisy toys and personal listening devices that can permanently damage their hearing. Toys that meet the safety standards of the American Society for Testing and Materials can produce sound up to 138 decibels, as loud as a jet taking off. Yet workplace rules require hearing protection for those exposed to noise above 85 decibels. A landmark study in 1975 found that children in classrooms on the noisy side of a school had lower reading scores than those whose classes were on the quiet side. Media and entertainment (M\&E) companies need to do more than react to today's challenges - they need to start driving operational change that will prepare them for the future of television. Ultimately, we see the future of television as a carefully crafted Omni screen experience that combines great content with equally compelling social and gaming techniques tailored to an individual viewer's stated and implicit preferences. This, we believe, is the key to winning the future of television in a world where consumers are in control.

\section{OBJECTIVES AND METHODOLOGY}

That the media is becoming more and more louder, is a foregone conclusion. The viewers are confounded by the loud programs and the Political discussions that dominate media coverage and programs. The purpose of this research is to find out the reasons for the above phenomenon. It has been observed that people generally speak louder than what they used to be for being heard because of the environmental noise. This is a new development and along with the silence of younger generation who are keyed to their mobile phones and other equipment interpersonal Communication has become difficult or rather skewed. On the other hand the agenda of politicians who appear in media interviews seem to be counter the opposition by hook or crook rather than suggest any new ideas for development. In this environment the present research paper tries to identify factors responsible for this change and how to take remedial actions to end the political and social apathy. The following specific objectives have been identified for the purpose of this research paper:

1. A brief analysis of environment leading to the present decibel levels.

2. The traditional role of media and the current engagement

3. How Changes in the political and social environment can counter this

4. A comprehensive review of how social changes can impact media.

5. Suggestions for future course of action.

The rising media concerns on Social developments and the ever elusive political responses are causing concerns for the common public. They would like to see their voted representatives taking more interest in their concerns and find answers to various questions raised by media. But this debate seems to be getting more murky by the passing day and never ending. 
This article attempts to highlight the social responsibility of all stake holders and suggest ways and means of better participation of all the stake holders in taking the country in the development path. The conclusions and suggestions are given at the end of this research paper.

\section{REVIEW OFLITERATURE}

Noise-induced hearing loss can come about in two ways: from a brief exposure to a very loud noise or from consistent exposure to moderate-level noise. Thus, there is much concern about the lasting effects of MP3 players that are turned up loud enough to block out surrounding sound, like street noise. An MP3 player at maximum volume produces about 105 decibels - 100 times as intense as 85 decibels, where hearing damage begins. (For every 10 decibels, sound intensity increases tenfold.) The National Institute for Occupational Safety and Health says 110 decibels can produce hearing damage after just 1 minute, 29 seconds of exposure. The League for the Hard of Hearing cautions that "noise levels above 85 decibels will harm hearing over time" and those levels above 140 decibels — the pain threshold — can damage hearing after just one exposure.

New bone-conduction headphones that hook over the ears and pass sound through the skull to the inner ear may not solve the problem. While they allow listeners to hear an oncoming car or a person speaking, users may turn up the volume to overcome ambient noise, damaging the 15,000 tiny hair cells in the inner ear that transfer sound energy to the brain. Once damaged, hair cells can neither be repaired nor replaced. The damage makes it difficult to hear high-pitched sounds, including certain speech sounds and the voices of women and children. Tinnitus, a continuous ringing, roaring or clicking in the ears, can also result. The League for the Hard of Hearing urges parents to encourage participation in quiet activities, like reading, watching family-oriented films, doing puzzles, making things with construction toys, playing educational computer games, drawing and painting, and visiting libraries and museums.

Several emerging trends will impact established business models for ad-supported, subscription and pay-per-use content monetization in TV channels because of the decibel levels created by content. Here are the six trends that we see as having the biggest impact on the future of television.

1. Storytelling will evolve to make better use of an omniplatform environment.

2. Ubiquitous screens will demand greater content mobility.

3. Social dynamics and synergistic experiences will drive more event-based viewing.

4. Innovation in program discovery and television controls will drive new techniques to cut through the clutter.

5. Bingeing will drive more innovation in measurement and personalization.

6. New entrants demanding unique content will drive innovation beyond the traditional studio system.

At a foundational level, the six key trends described above, will require M\&E (Music and Entertainment) companies and content providers to develop much richer relationships with viewers. To cultivate these relationships, affected M\&E industry players will need to invest in the technologies that will enable them to analyze audience data, deliver deeper engagement with advertising and prove incremental value to brands. Most importantly, they will need to offer a deeper engagement with the content experience itself in such a way that viewers will choose to pay (either directly, or through their active attention to ads) for content streaming services or ownership. They will also need to plan and execute strategies that adapt their supply chains, customer experiences, and analytics platforms to address these trends. 


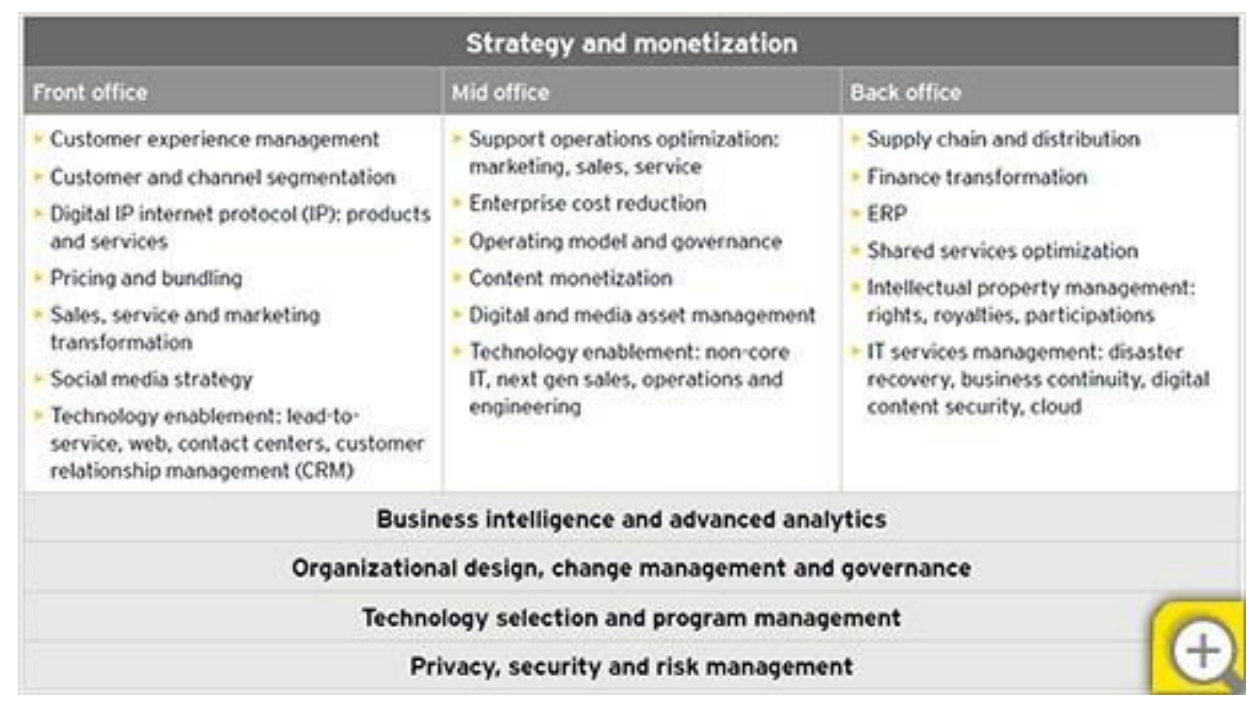

Figure 2: The future of television has implications for every Component of a media company

It's not difficult for a person to encounter sound at levels that can cause adverse health effects. During a single day, people living in a typical urban environment can experience a wide range of sounds in many locations, including shopping malls, schools, the workplace, recreational centers, and the home. Even once-quiet locales have become polluted with noise. In fact, it's difficult today to escape sound completely. The growing noise pollution problem has many different causes. Booming population growth and the loss of rural land to urban sprawl both play a role. Other causes include the lack of adequate anti-noise regulations in many parts of the world; the electronic nature of our age, which encourages many noisy gadgets; the rising number of vehicles on the roads; and busier airports.

Secondhand noise can also have a negative effect in the workplace. "Workers in the construction trades get exposure to noise not just from what they are doing but also from what is going on around them," says Rick Neitzel, director of communications for the National Hearing Conservation Association. "Electricians, for example, have a reputation as being a member of a quiet trade, but if they work all day next to a laborer who is using a jackhammer, it's going to have a harmful effect." Our modern industrialized society has spawned ubiquitous entertainment and sports industries with their boom boxes, "personal stereos" (Gap Kids now even offers a jacket with a built-in radio and speakers conveniently attached right in the hood), surround-sound movie theaters, loud TV commercials, and even louder commercials at sports stadiums crammed full of thousands of noisy fans. Even the countryside is not immune to the impact of noise pollution. According to the New York Center for Agricultural Medicine and Health in Cooperstown, a staggering $75 \%$ of farm workers have some kind of hearing problem, largely the result of long-term exposure to loud equipment.

"The noisy problems associated with air travel are concentrated in communities around airports, whereas motorways or high-speed trains - traveling, for instance, from north to south Europe - have the potential to disturb thousands of people living along the route day after day," says Ken Hume, a principal lecturer in human physiology at the Manchester Metropolitan University in England. Noise is indeed everywhere, and experts expect no decrease in noise levels, given the powerful impact of technology on modern life. Noise pollution is undesired sound that is disruptive or dangerous and can cause harm to life, nature, and property. It is often said that noise differs from other forms of pollution in that, unlike atmospheric pollutants for example, once abated, leaves no residual accumulation in the environment or the human body. Noise does leave behind its effects, however, and these can deteriorate after continued exposure to harmful sounds. The hazardous effects of noise depend on its intensity (loudness in decibels), duration, and frequency (high or low). High and low pitch is more damaging than middle frequencies, and white noise covering the entire frequency spectrum is less harmful than noise of a specific pitch. Noise may be ambient (constantly present in the background) or peak (shorter, louder sounds). 
Noise-induced hearing loss (NIHL) in humans is the major, though by no means only, problem stemming from noise pollution. In 1978 the U.S. Environmental Protection Agency (EPA) Office of Noise Abatement and Control estimated that around twenty million Americans were exposed daily to noise resulting in permanent hearing loss (EPA 1978). In 1990 about thirty million people in the USA were exposed daily to occupational noise levels above 85 decibels, compared with just over 9 million people in 1981. Exposure for more than 8 hours a day to sound in excess of 85 decibels is potentially hazardous. In Germany and other developed countries, as many as four to five million people, that is, 12 to 15 percent of all employed people, are exposed to noise levels of 85 decibels or more (World Health Organization 2001). The sources for noise prolusion are many, of which some are illustrated in Figures 3, 4, and 5. Loud, abrupt sounds can harm the eardrum, while sustained sounds at lower volume can damage the middle ear; both types of sounds can cause psychological damage. Noise disrupts sleep and communication, and numerous studies have documented the heartrelated, respiratory, neurological, and other physiological effects of noise. Stress, high blood pressure, anger and frustration, lower resistance to disease and infection, circulatory problems, ulcers, asthma, colitis, headaches, gastrointestinal disorders, and many other physiological and psychological problems have been linked directly to noise. In addition, children have been shown to suffer from slower language development and disruption of learning as a result of noise. In addition, noise can harm animals and the environment, as well as physical property. Livestock and pets are harmed by noise, as are animals in the wild. Noise can also disturb wildlife feeding and breeding. Noise-related property damage includes structural damage from vibrations induced by sound waves and economic harm in the form of lower property values. The true social costs of noise pollution also must include monetary losses from sickness, absenteeism, loss of productivity and earning capacity, and much more.

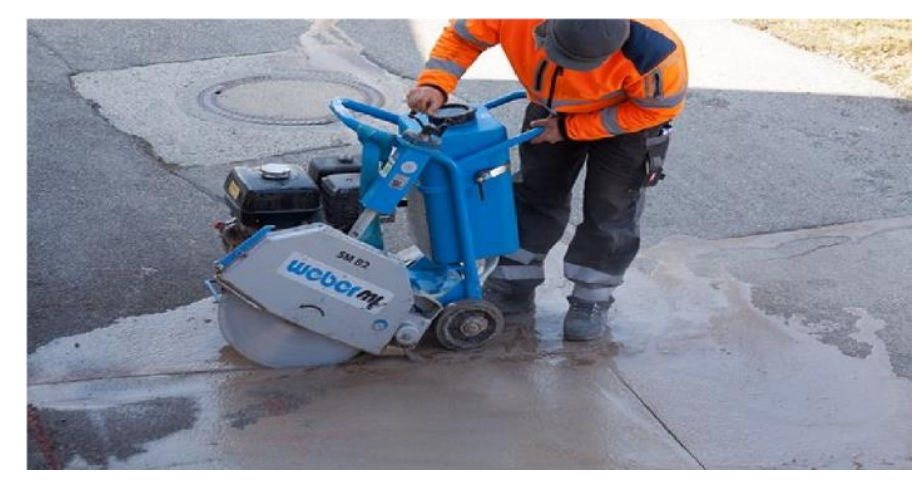

Figure: 3 Noise of Road Construction

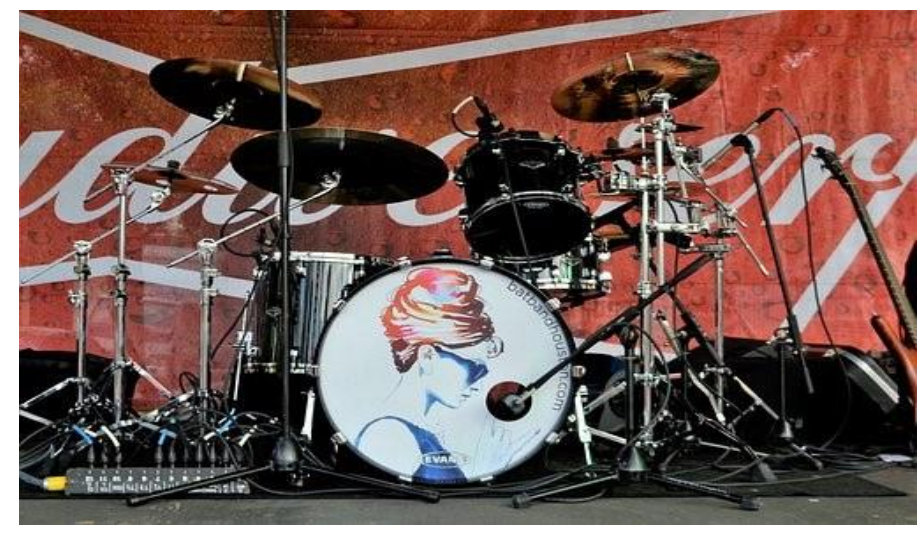

Figure: 4 Noisy Music with Drums 


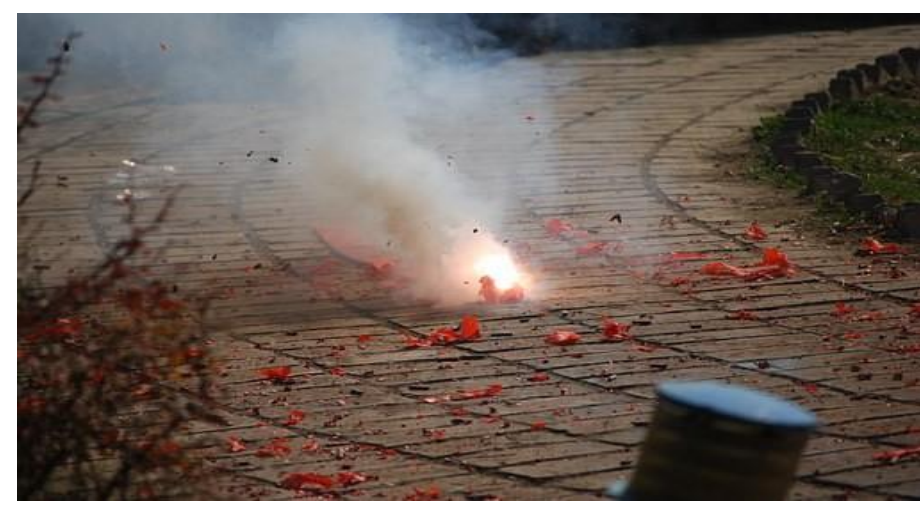

Figure: 5 Noise from Fire crackers

Noise pollution can be controlled through reduction at the source, interruption of transmission paths, or protection of the receiver. Reengineering machines and simply turning down volume when possible are methods of reduction at the source. Barriers, enclosures, and other forms of soundproofing can interrupt transmission paths. The use of hearing protection is the main form of receiver protection. Experts recommend a multifaceted approach, including appropriate training on the use of equipment and on why ear protection matters, enforcement of hearing-protection regulations, and the use of new technologies that reduce noise at the source (Lusk et al. 2004). Like many other environmental problems, addressing noise pollution is complicated by issues of shared responsibility and jurisdiction, making some conventional economic approaches less effective and inviting new interdisciplinary solutions. New active noise control (ANC) technologies may assist in dealing with noise pollution in the years ahead through the use of digital processors that convert analog sounds into digital signals, allowing computer generated "antinoise" to erase sound with sound (Alper 1991). Noise pollution is not new, but it has become more problematic with the developments associated with industrialization and urbanization. Commercial and industrial activities, construction, aircraft, vehicular traffic (highway and off-road), and the rapid increase in the use of machines and other technologies are all associated with noise pollution. Modern household appliances and lawn and gardening equipment are increasingly common sources of noise. Like many other forms of pollution, noise appears to disproportionately affect poor and disadvantaged minority communities, and so is also an environmental justice issue.

A study published last year whose results showed a relationship between attention deficit disorder by age seven and TV watching before three. This study was published in the journal Pediatrics in 2007 by F. Zimmerman and D. Christakis. Here's the abstract: Television and video/DVD viewing among very young children has become both pervasive and heavy. Previous studies have reported an association between early media exposure and problems with attention regulation but did not have data on the content type that children watched. We tested the hypothesis that early television viewing of 3 content types is associated with subsequent attention problems. The 3 different content types are educational, nonviolent entertainment, and violent entertainment. Participants were children in a nationally representative sample collected in 1997 and reassessed in 2002. The analysis was a logistic regression of a high score on a validated parentreported measure of attention problems, regressed on early television exposure by content and several important socio demographic control variables. Viewing of educational television before age 3 was not associated with attention problems 5 years later. However, viewing either violent or nonviolent entertainment television before age 3 was significantly associated with subsequent attention problems, and the magnitude of the association was large. Viewing of any content type at ages 4 to 5 was not associated with subsequent problems. The association between early television viewing and subsequent attention problems is specific to non-educational viewing and to viewing before age 3 . 


\section{ANALYSIS AND CONCLUSIONS}

It appears that society and people at large are getting noise conditioned as observed by 'The National Institute for Occupational Safety and Health' for a more noisy existence! From the MP3 players to the entire gamut of M\&S (Music and Entertainment) industry, solutions for bringing down the noise levels are being searched. This indeed is a warning signal against the invasion of privacy and the mental and physical hazards of loud noise levels. The impact on Future of TV has also been highlighted. Loud noises are supposed to produce hearing problems. As per the National Institute for Occupational Safety and Health 110 decibels can produce hearing damage after just 1 minute, 29 seconds of exposure. The League for the Hard of Hearing cautions that "noise levels above 85 decibels will harm hearing over a period of time" and that levels above 140 decibels — the pain threshold — can damage hearing after just one exposure.

The media is where the maximum decibel levels are pre-designed and produced. The traditional role of media has been one of informing public of intelligent choice of product and service. This soon turned out to be a game of Competition as more and more firms started manufacturing and marketing products of similar nature leading to cutthroat competition. The advertising and promotional media jumped into the fray and started making more and more noise increasing decibel levels of TV and radio media. This has led to the present situation of 'Noise Pollution'.

The current social environment is characterized by such competition and Marketers are more and more busy selling their wares at all costs. The social environment is changing due to digital proliferation and the youngsters getting addicted to devices which are almost always plugged on as if it is part of their body. Political dispensation in most of the countries is also distinguished by selfish interests instead of national priorities. This kind of Political and Social environment is not conducive to a calm and peaceful human existence. The word is full of competition and the strife induced thereof.

Social changes are necessary to build a healthy society for future. More than the competitive postures adopted by industries and nations, it would be worthwhile considering measures for the common welfare. Intolerance has to be replaced by an attitude of give and take and not only take, take and take more! Natural resources are bursting at their seams and unless there is an attitude of global welfare as opposed to globalization (which is in short one size fit for all!) Social changes are already impacting attitudes towards media. TV viewing and programs are strictly monitored in many countries so that youngsters have a positive attitude and direct their energies for future benefit of society and participate in nation building exercise. The digital devices are making them more and more personalized with less social contact and orientation. Media is not helping in this area, their contention being that they truly reflecting what are happening in society. Without impacting their earnings and TRP rates media can play a positive role in shaping consumption attitudes and participation of youth and solving the generation differences in a positive manner. Of the past is built the future. The present young generation is the future older generation of tomorrow!

Future is a continuation of the present and from a philosophic and practical point of view the present only exists and is relevant for future. It definitely depends on the Social will of people together in this planet to create a better future for all. 


\section{BIBLIOGRAPHY}

[1].Axelsson A, Jerson T. Noisy toys: A possible source of sensory neural hearing loss. Pediatrics 1985; 76: $574-578$.

[2].Airo E, Pekkarinen J, Olkinuora P. Listening to music with earphones: an assessment of noise exposure. Acta Acustica united with Acustica. 1996; 82(6):885-894.

[3].American Academy of Pediatrics, Committee on Environmental Health. Noise: a hazard for the fetus and newborn. Pediatrics 1977; 100: 724-727.

[4].American National Standard Institute . Determination of Occupational Noise Exposure and Estimation of Noiseinduced Hearing Impairment (S3.44-1996) American National Standards Institute; New York, NY: 1996.

[5].Babisch W, Beule B, Schust M, et al. Traffic noise and risk of myocardial infarction. Epidemiology 2005; 16 : 33-40.

[6].Berglund B, Lindvall T. (Eds.) Community Noise. Archives of the Center for Sensory Research. 1995; 2: 1-195.

[7].Berglund B, Lindvall T, Schwela D, editors. Guidelines for community noise. World Health Organization; Geneva, Switzerland: 1999

[8].Bluhm G, Nordling E, Berglind N. Road traffic noise and annoyance - - an increasing environmental health problem. Noise Health 2004; 6: 43-49.

[9].Carlos D. A different route to health: implications of transport policies. Brit Med J 1999; 318: 1686-1689

[10]. Clark, Charlotte, and Stephen A. Stansfeld. 2005. The Effect of Aircraft and Road Traffic Noise on Children's Reading. Literacy Today 44 (9): 24-25.

[11]. Carter NL. Transportation noise, sleep, and possible after-effects. Environ Int 1996; 22: 105-116.

[12]. Chung JH, Des Roches CM, Meunier J, et al.. Evaluation of noise-induced hearing loss in young people using a web-based survey technique. Pediatrics 2005; 115: 861-867

[13]. Committee on Environmental Health, American Academy of Pediatrics Handbook of Pediatric Environmental Health. Noise. Washington, DC, American Academy of Pediatrics, 2003

[14]. Danhauer JL, Johnson CE, Byrd A, DeGood L, Meuel C, et al. Survey of college students on iPod use and hearing health. J Am Acad Audiol. 2009;20:5-27.

[15]. Environmental Protection Agency. Information on levels of environmental noise requisite to protect public health and welfare with an adequate margin of safety. EPA/ONAC 550/9-74-004. U.S. Environmental Protection Agency. Washington, DC. 1974.

[16]. Evans, Gary W., et al. 2001. Community Noise Exposure and Stress in Children. Journal of the Acoustical Society of America 109 (3): 1023-1027.

[17]. Evans GW, Lepore SJ. Non-auditory effects of noise on children; a critical review. Children's Environments 1993; 10: $42-72$. 
[18]. Gershon RR, Neitzel R, Barrera MA, et al. Pilot survey of subway and bus stop noise levels. Urban Health 2006; 83: $802-812$.

[19]. Gunderson E, Moline J, Catalano P. Risks of developing noise-induced hearing loss in employees of urban music clubs. Am J Ind Med 1998; 31: 75-79.

[20]. Havas, Valerie. 2006. Noise! The Invisible Pollution. Current Health 232 (5): 10-11.

[21]. Lai, Patrick. 1996. Noise Pollution. In Major Environmental Issues Facing the 21 st Century, eds. Mary K. Theodore and Louis Theodore, 389-396. Upper Saddle River, NJ: Prentice Hall.

[22]. Lusk, Sally, et al. 2004. Acute Effects of Noise on Blood Pressure and Heart Rate. Archives of Environmental Health $59(8): 392-399$.

[23]. Staples, Susan L. 1997. Public Policy and Environmental Noise: Modeling Exposure or Understanding Effects. American Journal of Public Health 87 (12): 2063-2067.

[24]. Suter AH. Noise and its Effects. Administrative Conference of the United States, 1991.

[25]. Lee CSY, Fleming GG (2002), General Health Effects of Transportation Noise. U.S. Department of Transportation. Washington DC.

[26]. Ising H, Kruppa B. Health effects caused by noise: evidence from the literature from the past 25 years. Noise Health 2004; 6: 5-13.

[27]. Shapiro SA. The Dormant Noise Control Act and Options to Abate Noise Pollution. Administrative Conference of the United States, 1991. Available at:

[28]. Stansfeld S, Haines M, Brown B. Noise and Health in the Urban Environment. Rev Environ Health 2000; $15: 43-$ 82.

[29]. Passchier-Vermeer W, Passchier WF. Noise exposure and public health. Environ Health Perspect 2000; 108 (Suppl. 1): 123-131.

[30]. Stansfeld SA, Matheson MP. Noise pollution: non-auditory effects on health. Brit Med Bull 2003; 68: $243-257$.

[31]. Niskar AS, Kieszak SM, Holmes AE, et al. Estimated prevalence of noise-induced hearing threshold shifts among children 6 to 19 years of age: The third national health and nutritional examination survey 1988-1994, United States. Pediatrics 2001; 108: 40-43.

[32]. Sadhra S, Jackson CA, Ryder T, et al. Noise exposure and hearing loss among student employees working in university entertainment venues. Ann Occup Hyg 2002; 46: 455-463.

[33]. Van Kempen, EEMM, Kruize H, Boshuizen HC, et al. The association between noise exposure and blood pressure and ischemic heart disease: a meta analysis. Environ Health Perspect 2002; 110: 307-317.

[34]. Korte C, Ypma I, Tappen A. Traffic noise, environmental awareness, and pedestrian behavior. Environ Behav 1980; 12: 408-420. 
[35]. Stansfeld SA, Berglund B, Clark C, et al. Aircraft and road traffic noise and children's cognition and health: a cross national study. Lancet 2005; 365: 1942-1949.

[36]. Omlin S, Bauer GF, Brink M. Effects of noise from non-traffic-related ambient sources on sleep: review of the literature of 1990-2010. Noise Health, 2011;13:299-309.

[37]. Niskar AS, Kieszak SM, Holmes AE, Esteban E, Rubin C. Estimated prevalence of noise-induced hearing threshold shifts among children 6 to 19 years of age: the Third National Health and Nutrition Examination Survey, 1988-1994, United States. Pediatrics. 2001;108:40-43.

[38]. Sadhra S, Jackson CA, Ryder T, Brown MJ. Noise exposure and hearing loss among student employees working in university entertainment venues, Ann Occup Hyg. 2002; 46:455-463.

[39]. Levey S, Levey T, Fligor BJ. Noise exposure estimates of urban MP3 player users. J Speech Lang Hear Res. 2011; 54:263-277.

[40]. Mostafapour SP, Lahargoue K, Gates GA. Noise-induced hearing loss in young adults: the role of personal listening devices and other sources of leisure noise. Laryngoscope. 1998; 108:1832-1839.

[41]. U.S. Environmental Protection Agency. Information on levels of environmental noise requisite to protect public health and welfare with an adequate margin of safety (EPA/550/9-74-004) U.S. Environmental Protection Agency; Washington, DC: 1974.

[42]. World Health Organization, Burden of disease from environmental noise: quantification of healthy life years lost in Europe. World Health Organization; Geneva, Switzerland: 2011.

[43]. Schell LM, Gallo MV, Denham M, Ravenscroft J. Effects of pollution on human growth and development: an introduction. J Physiol Anthropol, 2006; 25:103-112.

[44]. Matheson M, Clark C, Martin R, van Kempen E, Haines M, et al. The effects of road traffic and aircraft noise exposure on children's episodic memory: the RANCH project. Noise Health, 2010; 12:244-254.

[45]. National Research Council. Technology for a Quieter America. The National Academies Press; Washington, DC: 2010.

[46]. National Institute on Deafness and Other Communication Disorders Noise-induced hearing loss in children at work and at play conference; Cincinnati, OH... 2006.

[47]. Lewis RC, Gershon RR, Neitzel RL. Estimation of permanent noise-induced hearing loss in an urban setting. Environ Sci Technol. 2013;47:6393-6399.

\section{WEB REFERENCES}

[1].http://www.wsj.com/video/why-competing-with-netflix-and-amazon-isimpossible/93BA6020-5E2E-45CE-879718E8274D60F4.html 
[2].http://www.nonoise.org/library/epahlth/epahlth.htm

[3].http://www.who.int/mediacentre/factsheets/fs258/en/.

[4].http://www.who.int/docstore/peh/noise/guidelines2.html.

[5].http://www.pubmedcentral.nih.gov/articlerender.fcgi?article=1253720.

[6].http://www.nonoise.org/library/suter/suter.html.

[7].http://www.nonoise.org/library/shapiro/shapiro.html.

[8].http://www.census.gov/hhes/www/housing/ahs/ahs99/tab28.html.

[9].http://www.lhh.org/hrq/24-1/village.htm

[10]. http://digitalcommons.unl.edu/archengfacpub/19. 